\title{
Impact of a New Metro Line: Analysis of Metro Passenger Flow and Travel Time Based on Smart Card Data
}

\author{
Xiao Fu $\mathbb{D}^{1}$ and Yu Gu $\mathbb{D}^{2}$ \\ ${ }^{1}$ School of Transportation, Southeast University, Nanjing 210096, China \\ ${ }^{2}$ Jiangsu Key Laboratory of Urban ITS, Jiangsu Province Collaborative Innovation Centre of Modern Urban Traffic Technologies, \\ School of Transportation, Southeast University, Nanjing 210096, China \\ Correspondence should be addressed to Xiao Fu; fuxiao@seu.edu.cn
}

Received 27 May 2018; Accepted 6 August 2018; Published 19 August 2018

Academic Editor: David Z. W. Wang

Copyright (C) 2018 Xiao Fu and Yu Gu. This is an open access article distributed under the Creative Commons Attribution License, which permits unrestricted use, distribution, and reproduction in any medium, provided the original work is properly cited.

\begin{abstract}
Over the past few decades, massive volumes of smart card data from metro systems have been used to investigate passengers' mobility patterns and assess the performance of metro network. With the rapid development of urban rail transit in densely populated areas, new metro lines are constantly designed and operated in recent years. The appearance of new metro lines may significantly affect passenger flow and travel time in the metro network. In this study, smart card data of metro system from Nanjing, China, are used to study the changes of metro passenger flow and travel time due to the operation of a new metro line (i.e., Line 4, opened on 18 January 2017). The impact of the new metro line on passenger flow distribution and travel time in the metro network is first analysed. As commuting is one of the major purposes of metro trips, the impact of the new metro line on commuters' trips is then explicitly investigated. The results show that the new metro line influences passenger flow, travel time, and travel time reliability in the metro network and has different impacts on different categories of commuters.
\end{abstract}

\section{Introduction}

Multimodal transit networks provide convenient and efficient ways for individuals' daily travel in congested urban areas. Metro system, as a major component of multimodal transit system, has been significantly developed in recent years in many cities with large populations. Taking Nanjing, one of the most densely populated cities in China, for instance, 6 new metro lines have been constructed and operated in Nanjing in the past decade and 11 new metro lines are planned to be developed in the next five years.

To study the passenger flow characteristics and evaluate the performance of urban transit network, a substantial body of literature has been developed on analysing the distribution of passenger flow and travel time based on smart card data. However, limited effort has been devoted to investigating the impact of new metro line on metro network and passengers. The development of new metro lines changes the topology of metro network and influences the accessibility of city area. The operation of new metro lines may affect passenger flows of existing metro stations. Passengers' travel times and travel time reliability may also change as a result of the expansion of metro network. As commuters are the majority of metro users in peak hours and are expected to benefit from the opening of new lines, the impact of new metro line on commuters' trips should be explicitly studied. In the literature, little attention has been given to the changes of commuters' spatial/temporal distributions and travel times after the opening of new metro lines.

In this study, a comprehensive analysis of metro passenger flow and travel time is presented on the basis of smart card data from Nanjing, China. The impact of new metro line on metro passenger flow and travel time is first analysed on the level of whole metro network. Spatial and temporal distributions of metro passenger flow in peak and nonpeak hours are investigated before and after the opening of the new line. The changes of passenger travel time and travel time reliability are also studied. To investigate the impact of the new metro line on commuters' trips, this study identifies and classifies the passengers commuting by metro and investigates the impact of the new metro line on flow distribution, travel time, 
and travel time reliability of different categories of metro commuters.

The outline of this paper is as follows. Section 2 presents a review of studies using smart card data and studies discussing the impact of new rail transit lines. Data used in this study are described in Section 3. Impacts of new metro line on passenger flow and passenger travel time are investigated in Sections 4 and 5. Conclusions and recommendations for future research are given in the last section.

\section{Literature Review}

2.1. Applications of Smart Card Data. Smart card data, which are passively collected by automated fare collection systems with the use of smart cards for transit services, are important data source for transport researchers. Because of the large quantity and high precision of smart card data, many researchers believe that such innovative data source can complement or even replace the traditional collected transport data such as travel survey data [1,2]. Existing transport studies based on smart card data mainly focus on three areas: analysis of passenger flow patterns, investigation of travel behaviours, and assessment of transit network performance.

Many studies are devoted to investigating the characteristics of metro passenger flow patterns based on smart card data. Smart card data record the entrance/exit stations and entrance/exit times of metro passengers, so the data are widely used to investigate and visualize the spatial and temporal distributions of metro passenger flow [3-5]. Based on the historical entrance and exit passenger flow records, the future passenger flow can also be predicted with smart card data $[6,7]$.

Smart card data can also be used to analyse travel behaviours and extract travel patterns of transit users. Travel behaviours in transit networks can be investigated such as transit ridership and origin-destination (OD) choices $[8,9]$, train and route choices [10, 11], and transfer behaviours [12]. Based on the investigation of travel behaviours, many studies are conducted to extract individuals' spatial/temporal travel patterns [13-15] and mobility patterns [16-18]. The dynamics of travel behaviours and the variation of travel pattern were also studied [19-22]. Some other studies focused on the regularity of individual travel pattern, using smart card data to classify transit passengers [23, 24].

In addition, smart card data can also be applied to investigate transit network performance such as the passenger travel time and the service reliability of transit systems. For instance, some studies investigated the spatial and temporal distribution of trip travel times [25], travel time differences between different transit modes [12], and splitting and estimation of metro travel time [26]. The service reliability of transit systems can also be derived based on smart card data. Comparing passengers' entrance/exit times to the transit schedules, researchers can select schedule deviation of vehicles or at-stop waiting time of passengers to measure the service reliability [27]. The concept of travel time reliability is widely employed to evaluate service reliability of transit systems from the perspective of individual passengers. The travel time reliability metrics include the schedule-based metrics such as excess journey time and reliability buffer time $[28,29]$, as well as statistical metrics such as standard deviation (SD) and coefficient of variation (CV) of travel time $[4,30-33]$.

2.2. Impact of New Rail Transit Lines. Construction of a new rail transit line may result in changes of individuals' travel choice behaviour. The change in mode choice attracts much attention in the literature. Senior [34] analysed the modal shift from bus and private vehicles to the light rail transit based on household survey and census data. Cao and Schoner [35] explored the impact of new light rail transit line on transit use. Harvey et al. [36] investigated people's willingness to travel by the newly built high speed rail line. Gadziński and Radzimski [37] combined household survey data with property sales transactions data to investigate the effect of a new tram on households' mode choice behaviour. In addition to studying the mode choice change, Saidi, Wirasinghe, and Kattan [38] assessed the changes in passengers' cost after introducing a new rail line based on job distribution data and origin-destination data. Hong, Boarnet, and Houston [39] adopted sociodemographic data, travel survey data, and activity data to investigate the impact of a new light rail transit line on individuals' travel behaviour.

Besides the studies focusing on the change of travel behaviour, a few studies reveal the impact of new metro lines on passenger flow. Li [40] analysed changes in passenger flow pattern caused by different types of new metro lines. Based on smart card data, Liu, Yao, and Li [41] analysed the relationship between metro network expansion, land use of station neighbourhood, and the growth of station passenger flow.

However, existing studies mainly focus on the change of passenger flow distribution on the network level, while little attention has been paid to the impact of new lines on different individuals. Transportation analyses which are not conducted from individuals' perspective may be biased as they fail to depict individuals' real travel experience [42]. Some studies have been made to investigate the performance of urban transportation network from the perspective of individual travellers using different kinds of data sources [33, 43]. In densely populated urban areas, as a large proportion of passengers' daily travels are made by metro, the opening of a new metro line may significantly influence some individuals' daily travel patterns while other individuals may not be affected. For giving a comprehensive analysis of the impact of new metro line on metro passenger flow and travel time, the analysis in this study is first conducted on the network level to present an overview of the metro system and investigate the changes of passenger flow and travel time after the new line opening. Further analysis focuses on metro commuters. Effort has been devoted to categorizing commuters based on their OD choices and evaluating the impact of the new metro line on different categories of commuters.

\section{Study Area and Data Collection}

Nanjing is one of the largest cities in China with a population of about 8 million. In 2005, the first metro line 


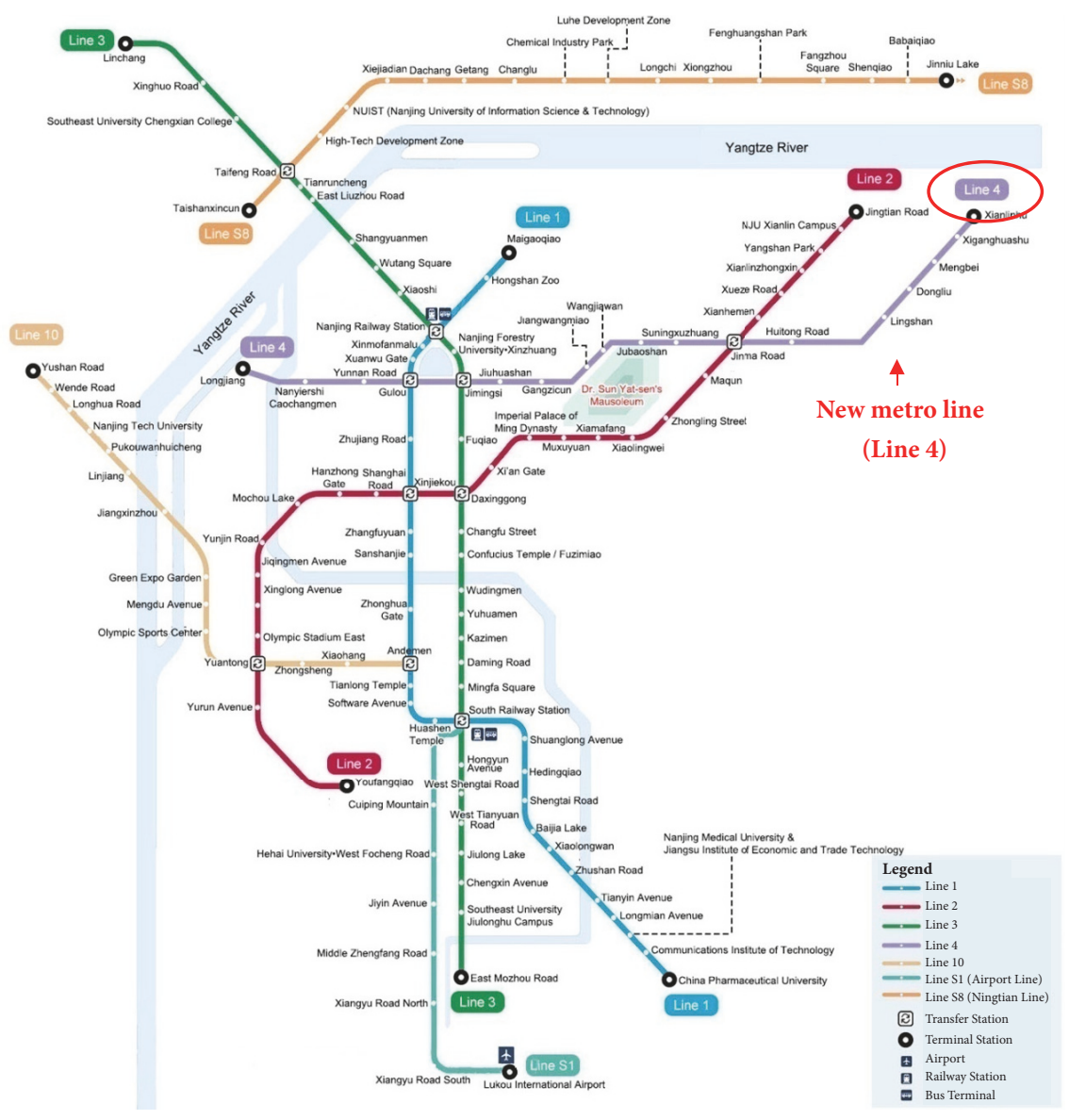

FIGURE 1: Nanjing metro network.

TABLE 1: Examples of smart card data used in this study.

\begin{tabular}{lcccr}
\hline Time of Entry & Station of Entrance & Time of Exit & Station of Exit & 7 \\
\hline 2017/1/1 10:10:21 & 14 & $2017 / 1 / 110: 30: 21$ & 16 & 976072959331 \\
2017/1/1 20:27:50 & 14 & $2017 / 1 / 120: 34: 52$ & 101 & 976072959320 \\
2017/1/1 11:56:56 & 37 & $2017 / 1 / 112: 46: 34$ & 50 & 993172764630 \\
2017/1/1 21:10:28 & 14 & $2017 / 1 / 122: 03: 25$ & 970672806438 \\
\hline
\end{tabular}

began operation in Nanjing. In the past decade, Nanjing metro network expands rapidly. An overview of Nanjing metro network is extracted from Internet and shown in Figure 1. Line 4 of Nanjing metro system was opened on 18 January 2017, which is the latest line operated. After the opening of Line 4, there are 7 metro lines and 139 stations in operation in Nanjing. The operating mileage of Nanjing metro network is $258 \mathrm{~km}$, and the average daily ridership in January 2017 is about 2.1 million.

To explore the impact of new metro line (i.e., Line 4) on metro passenger flow and travel time in densely populated urban areas, the data used in this study are records of smart cards used by metro passengers in Nanjing from January to February 2017, 61 million records in total. Data of the two months are used because the two months cover the periods before and after the opening of Line 4. Data of two consecutive months guarantee the stability of passengers' travel choice behaviour.

Smart card data contain complete entrance and exit records (including location and time) of each passenger, as shown in Table 1 . Take the first record in Table 1 as an example; the record indicates that the passenger entered the metro system from station No. 14 (i.e., Nanjing Railway Station) at 10:10:21 on 1 January 2017 and exited from station No. 7 (i.e., Sanshanjie) at 10:30:21. Data cleaning is conducted to exclude incomplete and invalid data before analysis.

\section{The Impact of New Metro Line on the Metro Network}

The operation of the new metro line may influence metro passenger flow distribution. It can be seen from Figure 1 that Line 4 has intersections with three lines (i.e., Lines 1, 2, 




FIGURE 2: Daily metro passenger flow before and after Line 4 opening.

and 3) which pass through central areas of the city. Before the opening of Line 4, the three lines took the majority of passenger flows in the metro network. Line 4 is expected to share passenger flows with Lines 1-3 and alleviate the crowding effect at some metro stations in central business district (CBD). Thus, a need is evident to investigate the change of passenger flow in metro network after Line 4 opening.

In this section, spatial and temporal analysis of passenger flow are conducted to show the passenger flow distributions in the whole metro network before and after the opening of Line 4. Travel time and travel time reliability in the metro network are also investigated to show the impact of the new line.

\subsection{Metro Passenger Flow Distribution}

4.1.1. Temporal Distribution of Metro Passenger Flow. On the basis of smart card data from 1 January to 28 February 2017, the daily flows of passengers using smart cards on Line 4 and on the whole metro network are shown in Figure 2. It is obvious from Figure 2 that the passenger flow varies from day to day. The passenger flow on workday is significantly higher than that at weekend, which implies that a large portion of metro passengers are commuters. Thus, in Section 5, explicit analyses of commuters' flow distributions and travel times are given.

It can also be seen from Figure 2 that the number of passengers increases after Line 4 opening. Before the opening of Line 4, the maximum daily passenger flow of the whole metro network is 1.33 million on workday and 1.05 million at weekend. After the opening of Line 4, the maximum passenger flows on workday and at weekend increase to 1.40 million and 1.09 million, respectively. The maximum passenger flow of Line 4 reaches 0.10 million on 24 February 2017.

Please note that passenger flow decreases dramatically during 21 January and 5 February as many residents leave Nanjing during Chinese New Year. Thus, data of the period affected by Chinese New Year are excluded from analysis

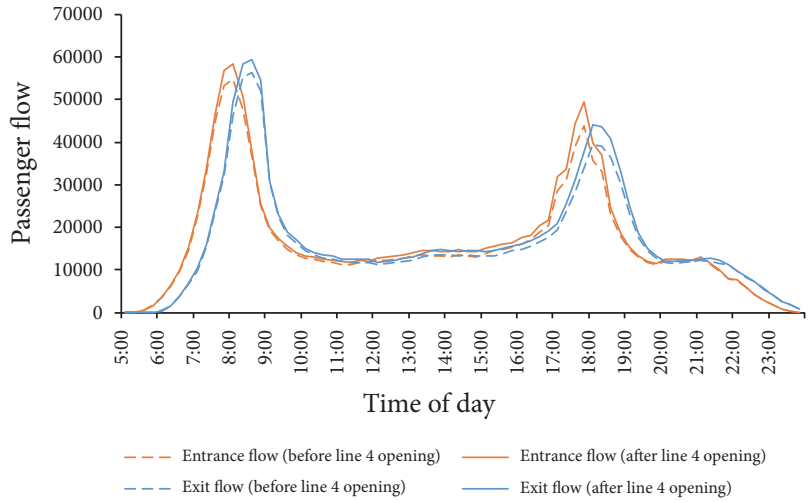

FIGURE 3: 15 min metro passenger flow distribution before and after Line 4 opening.

in this study to facilitate essential ideas without loss of generality. The study period is then divided into two parts: (a) 1 Jan 2017 to 17 Jan 2017 (the period before Line 4 opening); (b) 18 Jan 2017 to 20 Jan 2017 and 6 Feb 2017 to 28 Feb 2017 (the period after Line 4 opening).

In addition to the daily fluctuation of passenger flow, the entrance/exit flow in metro network also varies greatly at different times of day. Figure 3 shows the average $15 \mathrm{~min}$ passenger flow on workdays before and after Line 4 opening. Increase of entrance/exit flow can be found after Line 4 opening due to the expansion of network capacity. It can also be seen from Figure 3 that there are two peaks of passenger flow on workdays, i.e., 7:00-9:00 in the morning and 17:0019:00 in the afternoon. To capture the different conditions of metro network, it is necessary to analyse metro passenger flow and travel time in both peak hours and nonpeak hours.

4.1.2. Spatial Distribution of Metro Passenger Flow. Figure 4 shows the average daily exit flows of metro stations before and after the opening of Line 4 based on kernel density estimate.

The passenger flows at the stations highlighted in red circles vary significantly due to the opening of Line 4 . It can be seen that the crowding at the stations in CBD (i.e., the red 


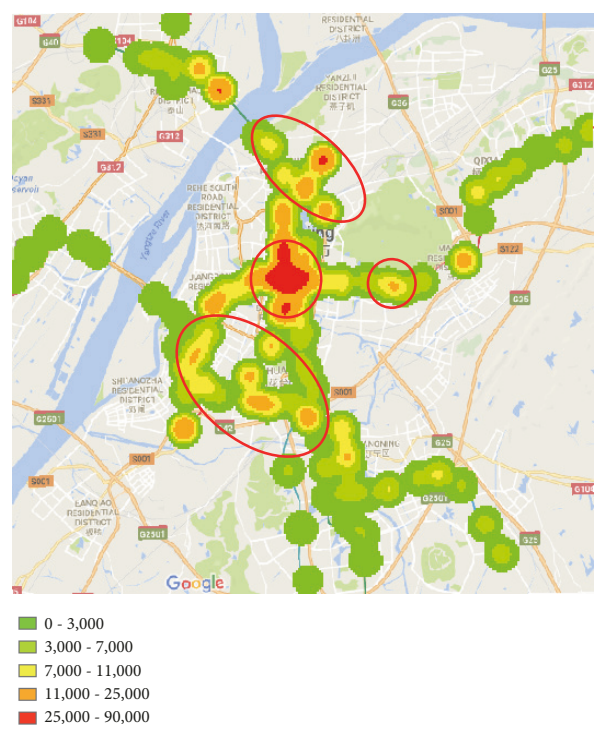

(a) Before Line 4 opening

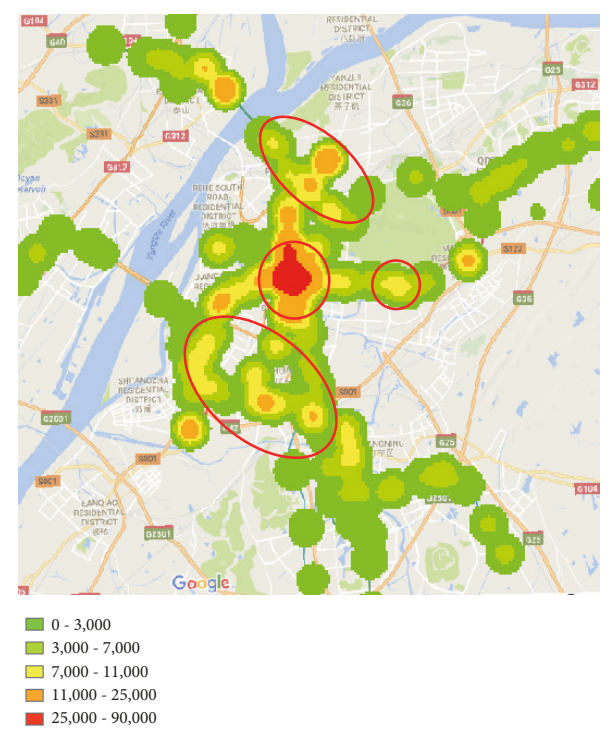

(b) After Line 4 opening

Figure 4: Spatial distribution of metro passenger flow before and after Line 4 opening (map source: Google Maps).

circle in the centre of the figure) is alleviated after the opening of Line 4. Several stations on other lines (highlighted in other red circles) share fewer passenger flows after the opening of Line 4. Thus, Line 4 attracts more individuals to metro network while contributing to the whole network by sharing a large number of passengers and reducing the crowding at several existing metro stations.

To explicitly investigate the impact of Line 4 on spatial distribution of passenger flow, the metro stations significantly affected by Line 4 are identified as follows.

Denote the mean and the SD of daily passenger flow from station $i$ to station $j$ before Line 4 opening as $f_{i j}^{\mathrm{b}}$ and $\sigma_{i j}^{\mathrm{b}}$, respectively:

$$
\begin{aligned}
f_{i j}^{\mathrm{b}} & =\frac{\sum_{n=1}^{N^{\mathrm{b}}} f_{i j}^{n \mathrm{~b}}}{N^{\mathrm{b}}}, \\
\sigma_{i j}^{\mathrm{b}} & =\sqrt{\frac{\sum_{n=1}^{N^{\mathrm{b}}}\left(f_{i j}^{\mathrm{b}}-f_{i j}^{n \mathrm{~b}}\right)^{2}}{\left(N^{\mathrm{b}}-1\right)}},
\end{aligned}
$$

where $N^{\mathrm{b}}$ is the number of days of the study period before Line 4 opening, and $f_{i j}^{n b}$ is the passenger flow on day $n$.

The mean of passenger flow from station $i$ to station $j$ after Line 4 opening (denoted as $f_{i j}^{a}$ ) can be obtained as

$$
f_{i j}^{\mathrm{a}}=\frac{\sum_{n=1}^{N^{\mathrm{a}}} f_{i j}^{n \mathrm{a}}}{N^{\mathrm{a}}}
$$

where $N^{\mathrm{a}}$ is the number of days of the study period after Line 4 opening.

In this study, if $f_{i j}^{a}$ exceeds the normal fluctuation ranges

$$
\begin{array}{r}
f_{i j}^{\mathrm{a}}>f_{i j}^{\mathrm{b}}+\beta \cdot \sigma_{i j}^{\mathrm{b}} \\
\text { or } f_{i j}^{\mathrm{a}}<f_{i j}^{\mathrm{b}}-\beta \cdot \sigma_{i j}^{\mathrm{b}},
\end{array}
$$

the OD stations are viewed to be affected by Line $4 . \beta$ is a parameter associated with the normal fluctuation ranges. In this study, the fluctuation range is set as $95 \%$; thus $\beta$ is 1.64 . Setting the destination $j$ as Gulou (a station located in CBD with a large number of passenger flows), Figure 5 shows the stations affected by Line 4 in peak and nonpeak hours.

As shown in Figure 5, the passenger flow travelling to CBD is significantly influenced by the operation of Line 4. From Figure 5(a), it can be seen that stations on Line 3 significantly attract more passengers to $\mathrm{CBD}$, while the passenger flows of many stations on Line 1 and Line 2 decreased. The reason is that Line 2 is spatially parallel to the new metro Line 4 , and passengers originally travelling by Line 2 might change to use Line 4 . The shift of passenger flow from Line 1 to Line 3 can be explained by the decreased travel time from Line 3 to CBD, which will be demonstrated in Section 4.2. Comparing Figures 5(a) and 5(b), it can be found that the passenger flow distribution in nonpeak hours is relatively more stable than that in peak hours, indicating that commuting trips are significantly influenced by the new metro line.

4.2. Travel Time in the Metro Network. The introduction of a new metro line probably has impacts, as expected, on passengers' activity and travel choice behaviour as the accessibility/connectivity of activity locations and transit stations changes [44]. As a reliable transport mode which does not suffer from road traffic congestion, metro is one of the best choices for commuters who work in CBD. In a city with similar size of Nanjing, the 30-minute coverage area of metro stations in CBD is important to commuters. Figure 6 shows the travel times from different metro stations to $\mathrm{CBD}$ with a travel time less than 30 minutes. Apparently, the number of stations within the 30-minute coverage area greatly increases due to the opening of Line 4 . The travel 


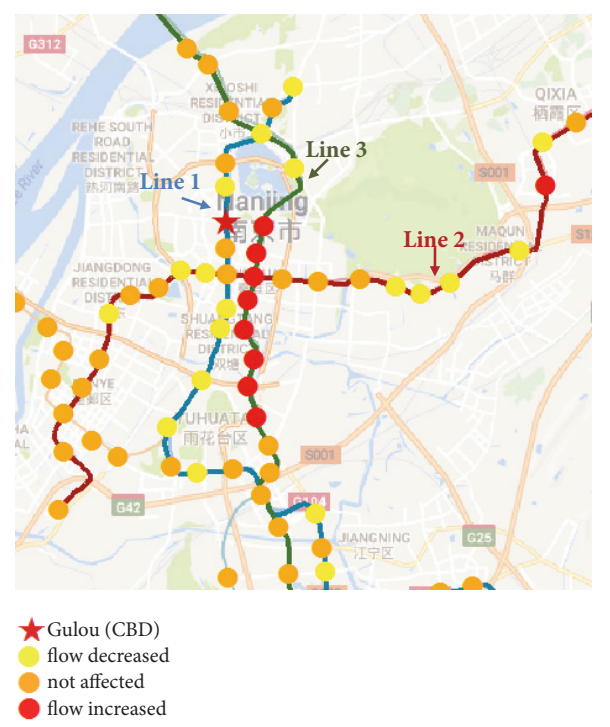

(a) Peak hours

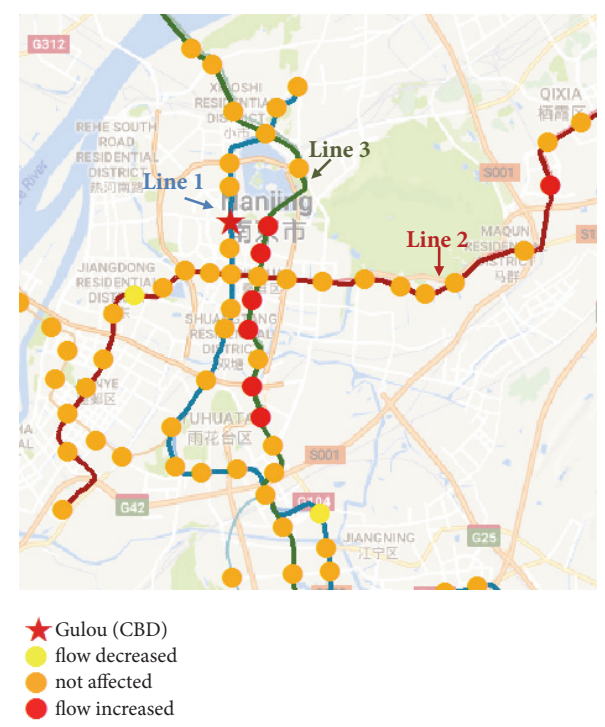

(b) Nonpeak hours

FIGURE 5: Change of passenger flow at metro stations after Line 4 opening (map source: Google Maps).

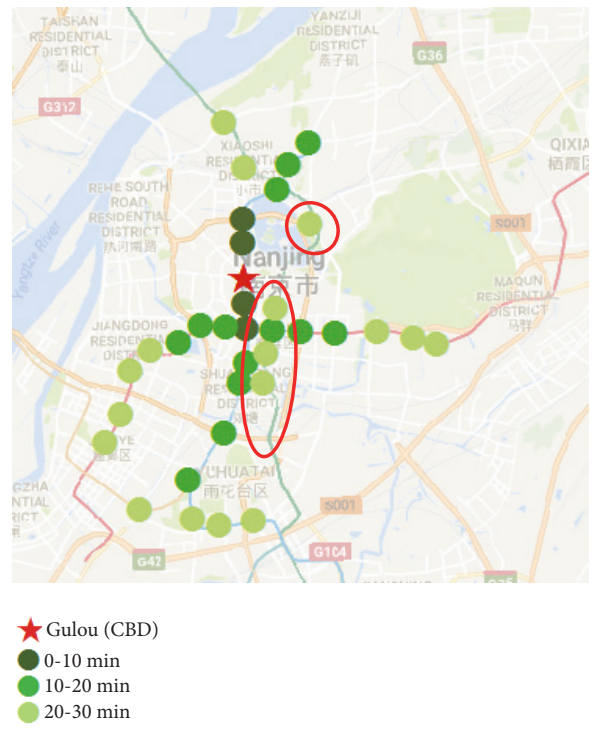

(a) Before Line 4 opening



(b) After Line 4 opening

FIGURE 6: Travel times from metro stations to CBD (map source: Google Maps).

times from many stations on Line 3 (which are highlighted by red circles) to CBD also decrease after Line 4 opening, while the travel times from stations on Line 1 to CBD remain stable. Hence, many passengers choose Line 3 to travel to CBD instead of Line 1 . The shift of passenger flow from Line 1 to Line 3 can be found in Figure 5 .

In metropolitan areas, travel times in transit networks generally vary from day to day. Many empirical studies revealed that individuals, especially commuters, indeed consider the travel time uncertainty as a risk for their travels. To reduce the risk of late arrival, individuals may have concerns on the probability that a trip can be successfully fulfilled within a given travel time, referred to as travel time reliability in the literature. Therefore, the travel time reliability in metro network should be explicitly explored with real data.

In this study, the coefficient of variation (CV) of travel time is selected as the measure of travel time reliability. The travel time reliability within OD pair $i j, c v_{i j}$, can be expressed as

$$
c v_{i j}=\frac{\sigma_{i j}}{t_{i j}}
$$

where $\sigma_{i j}$ and $t_{i j}$, respectively, denote the SD and the mean of travel time between $i$ and $j$. A higher $c v_{i j}$ indicates lower travel time reliability. 


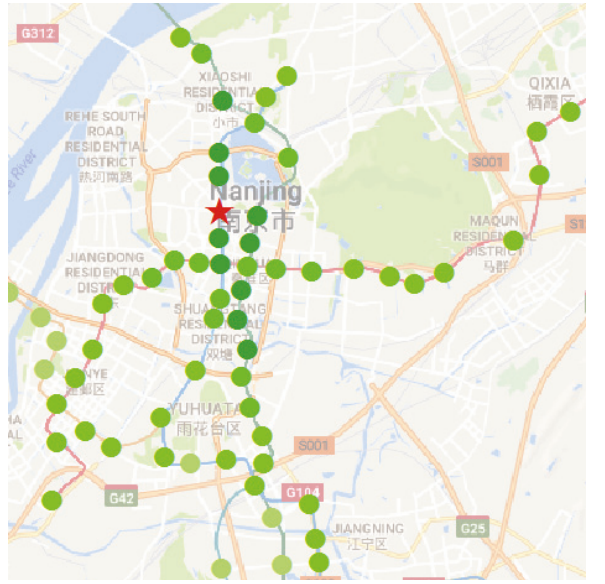

$$
\begin{aligned}
& \star \text { Gulou }(\mathrm{CBD}) \\
& \mathrm{cv}<=0.1 \\
& 0.1<\mathrm{cv}<=0.15 \\
& 0.15<\mathrm{cv}<=0.2 \\
& 0.2<\mathrm{cv}<=0.25 \\
& \mathrm{cv}>0.25
\end{aligned}
$$

(a) Peak hours, before Line 4 opening

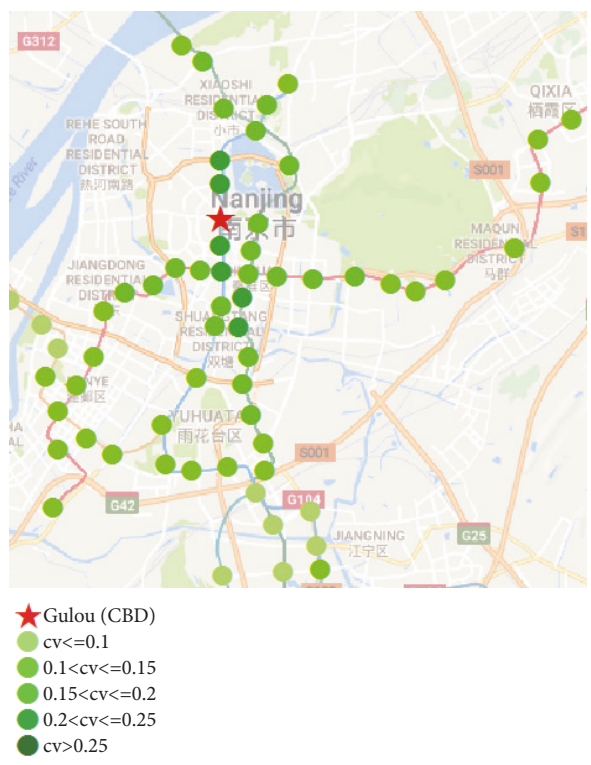

(c) Nonpeak hours, before Line 4 opening

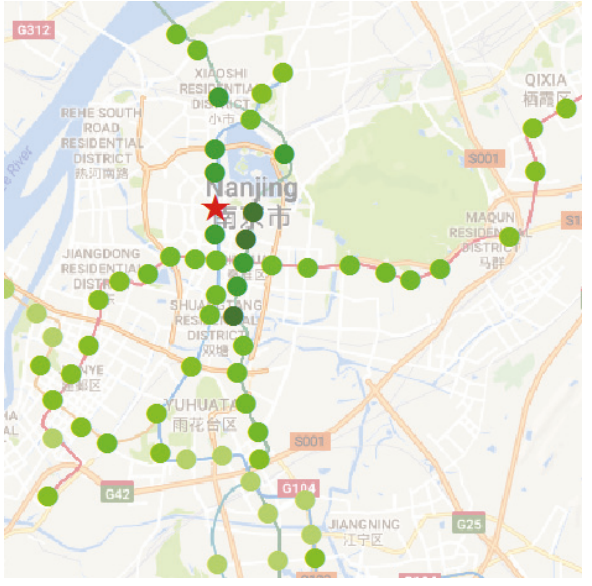

Gulou (CBD)
$\mathrm{cv}<=0.1$
$0.1<\mathrm{cv}<=0.15$
$0.15<\mathrm{cv}<=0.2$
$0.2<\mathrm{cv}<=0.25$
$\mathrm{cv}>0.25$

(b) Peak hours, after Line 4 opening

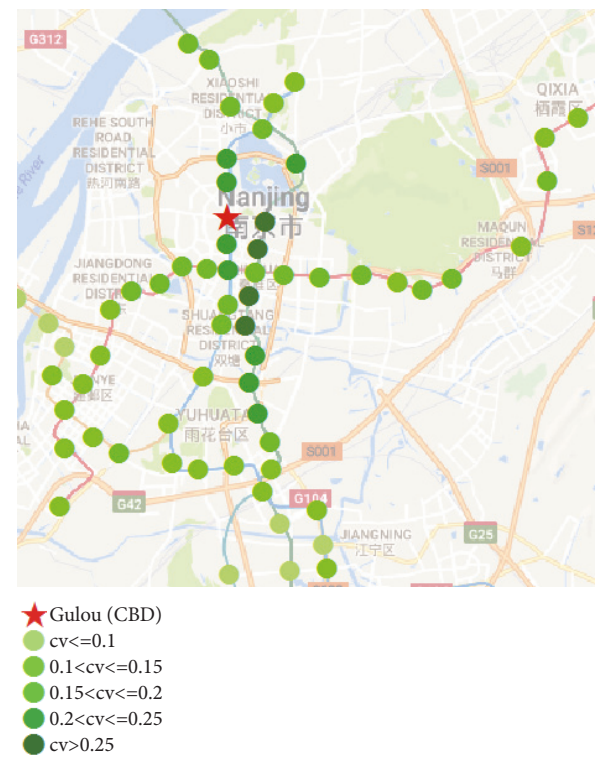

(d) Nonpeak hours, after Line 4 opening

Figure 7: Travel time reliability from metro stations to CBD (map source: Google Maps).

Based on the trip travel times extracted from smart card data before and after the opening of Line 4, the travel time reliability from all stations to CBD can be analysed. Figure 7 shows the CVs of travel times during peak and nonpeak hours before and after Line 4 opening. A light colour of a station is with a small value of $\mathrm{CV}$, which indicates the travel time from this station to CBD is quite reliable. The crowding effect during peak hours may reduce travel time reliability because some individuals are not able to get on the first arriving vehicles; however, the frequency of metro service in peak hours is higher than that in nonpeak hours. Thus, comparing Figures $7(a)$ and 7 (c) or comparing Figures 7(b) and 7(d), it can be found that there is no identical trend for all stations from peak to nonpeak hours in terms of travel time reliability.

Comparing Figures 7(a) and 7(b) or comparing Figures 7(c) and 7(d), it can be found that the opening of Line 4 surprisingly leads to decreased travel time reliability for many stations, especially the stations on Line 3 . The finding can be attributed to the increased transfer choices introduced by Line 4 . Many individuals prefer to transfer more times for shortening the travel time after Line 4 opening, while transfers bring random factors such as stochastic waiting and walking time.

The analysis in this section aggregates passengers in the whole metro network, which is unable to reveal the flow 
distribution and the travel time of different passengers before and after the opening of the new line. In Section 5, analyses of passenger flow and travel time focusing on commuters with different OD choices are conducted.

\section{The Impact of New Metro Line on Metro Commuters}

The analysis of passenger flow on the whole metro network level indicates the large passenger flow during peak hours in workdays, implying that commuters are the majority of metro users. Therefore, the spatial and temporal distribution of metro commuter flows and commuters' travel times deserve further analysis. The travel time reliability, which is a major concern for commuters' daily travel, should also be investigated before and after the opening of the new metro line.

In this section, analysis is conducted to investigate passenger flow and travel time changes for different categories of commuters.

5.1. Classification of Commuters. As commuting is a regular activity conducted by commuters in workdays, this study defines metro commuting as metro trips conducted by passengers between fixed ODs during peak hours of workdays. The metro commuters are defined as the passengers who conduct no less than one metro commuting trip every workday.

As the commuters' choices of entrance/exit station may change after introducing Line 4 , the commuters can be further divided into three groups based on the changes of their entrance/exit stations (i.e., ODs). The three groups are as follows: (1) commuters whose entrance and exit stations are not changed and not on Line 4 throughout the whole study time period; (2) commuters whose entrance and exit stations are not changed but the entrance/exit stations are intersections of Line 4 and other lines; (3) commuters whose entrance/exit stations are changed from stations on other lines to stations on Line 4 after Line 4 opening. The three groups, respectively, represent the commuters whose ODs are not affected, indirectly affected, and directly affected by the opening of Line 4.

Based on above criteria, 8543,588 , and 639 passengers are identified as groups 1,2 , and 3 commuters, respectively. The distributions and travel times of the commuters in different groups are further investigated. The impacts of new metro line on different groups are discussed.

\subsection{Passenger Flow Distribution of Different Groups of Commuters}

5.2.1. Temporal Distribution of Different Groups of Commuters. The temporal distributions of the three groups of commuters over a day are presented in Figure 8. From the entrance/exit passenger flow profiles, it can be found that the operation of Line 4 exerts different degrees of impacts on the three groups of commuters. A significant growth in the flow of group 3 commuters can be found after Line 4 opening. However, the distributions of group 1 and group 2 passenger flows remain almost unchanged. The new metro line generates more commuting trips by providing more choices of $\mathrm{O} / \mathrm{D}$ stations overall, but the commuters who have fixed OD stations and do not need to use the new line are hardly influenced.

As regards passenger travel time, hardly any change is observed in group 1 after Line 4 opening. A slight difference can be found between the travel times of group 2 before and after Line 4 opening. Although group 2 does not change ODs after Line 4 opening, the travel time of group 2 changes a little because their O/Ds are transfer stations with Line 4 . The passenger flows in these transfer stations change after Line 4 opening which may lead to the travel time change. As for group 3, it can be seen that the travel time varies a lot after Line 4 opening. The travel times at different times of day are significantly different from the travel times before Line 4 opening. As group 3 changes $\mathrm{O} / \mathrm{Ds}$ after Line 4 opening, the travel time changes accordingly.

5.2.2. Spatial Distribution of Different Groups of Commuters. Figure 9 depicts the cumulative number of trips with respect to the proportion of ordered OD pairs. It can be seen that a great number of trips are conducted between a small proportion of OD pairs. For instance, about $70 \%$ of the trips of group 1 are conducted between $10 \%$ OD pairs, implying that the majority of commuters' trips are between a few ODs. In addition, comparing to the trips in nonpeak hours, trips in peak hours are generated between fewer OD pairs, indicating that the spatial distribution of commuter flow concentrates in a limited number of ODs in peak hours. This phenomenon is more obvious in the morning peak than the afternoon peak, as commuters have more destination choices after work in the afternoon.

Comparing the distribution curves before and after Line 4 opening, we can find that the opening of Line 4 has different degrees of impact on the spatial distributions of different groups of commuters. The spatial distribution of group 1 is scarcely influenced. The spatial distribution of group 2 is less influenced in peak hours but more influenced in nonpeak hours, indicating that group 2 commuters have more OD choices in their spare time after Line 4 opening. Apparently, the impacts of Line 4 on the spatial distribution of group 3 are significant in both peak and nonpeak hours as group 3 changes $\mathrm{O} / \mathrm{D}$ stations after Line 4 opening.

\subsection{Travel Time Reliability of Different Groups of Commuters.} It is widely recognized that the analysis of travel time reliability should focus on individual passengers [45, 46]. In this section, the travel time reliability of each commuter group is investigated. The impacts of new metro line on travel time reliability of different groups of commuters are discussed.

Being consistent with Section 4.2, the average CV of each group of commuter's travel time is obtained to indicate the metro travel time reliability. $\mathrm{CV}$ of individual $k, c v_{k}$, can be expressed as

$$
c v_{k}=\frac{\sigma_{k}}{t_{k}}
$$



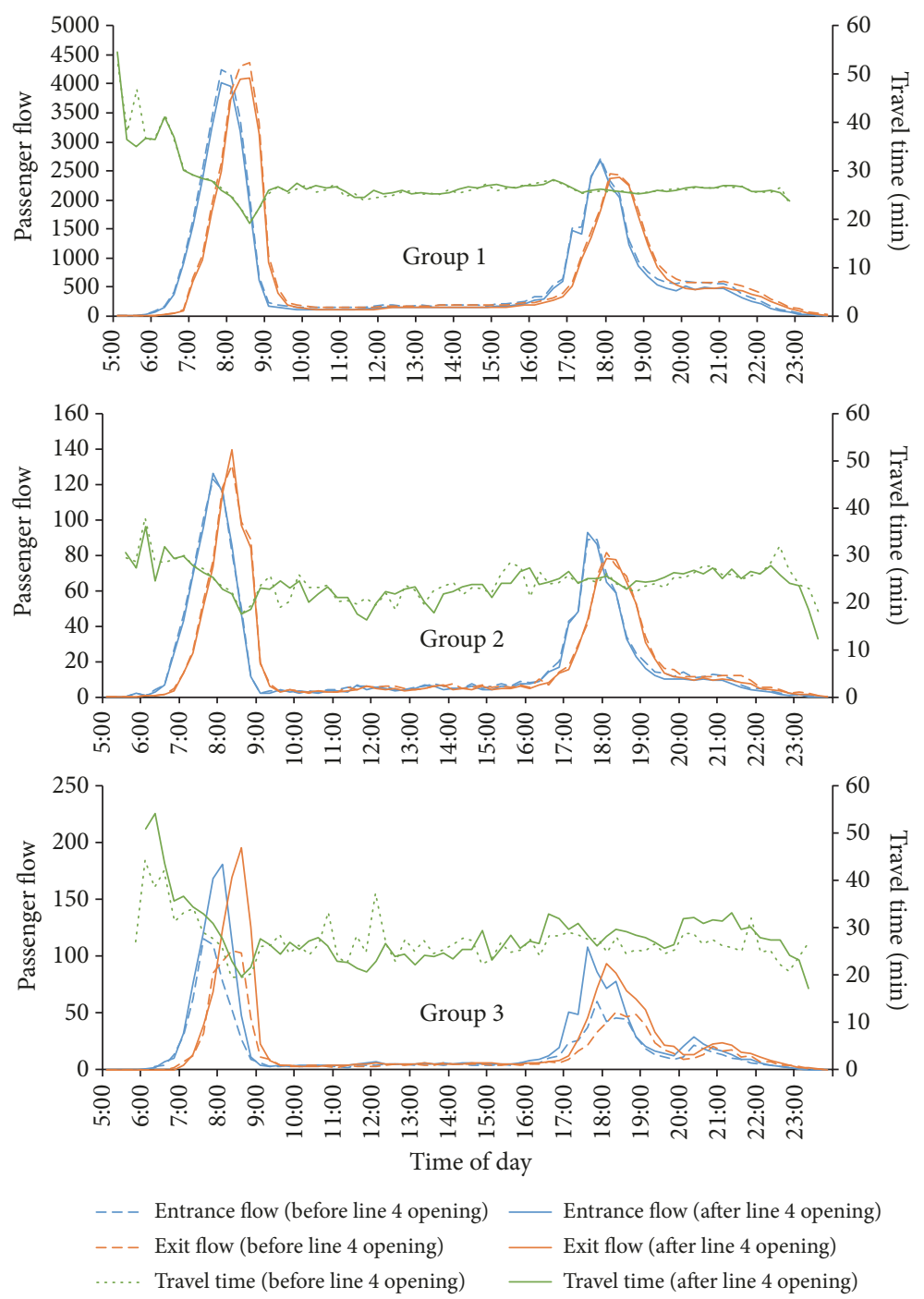

FIGURE 8: 15 min flow distributions of different groups of commuters and their travel times before and after Line 4 opening.

where $\sigma_{k}$ and $t_{k}$, respectively, denote the SD and the mean of $k$ 's metro travel time between his commuting OD.

The mean and the SD of commuting time of each group before and after Line 4 opening are investigated and shown in Figure 10. As linear lines fit the trends well and the slope of line can intuitively depict the travel time reliability, linear trend lines are used in Figure 10. It can be found from Figures 10 (a) and 10(b) that the mean and the SD of travel time of group 1 are hardly influenced by the opening of Line 4 , as the OD choices of group 1 are not affected by Line 4 .

Comparing Figures 10(c) and 10(d), it can be seen that the distribution of data points in Figure $10(\mathrm{~d})$ is more concentrated around the trend line, indicating that the travel time variability of group 2 is more predictable. This is because Line 4 shares a considerate number of passengers travelling through the transfer stations (i.e., group 2's O/Ds). Thus, the variability of travel time is mainly associated with travel distance instead of other incidents such as overcrowdings at stations.
From Figures 10(e) and 10(f), it can be found that the slope of trend line after Line 4 opening is obviously lower than that before Line 4 opening, indicating that the introduction of Line 4 raises the travel time reliability of group 3 commuters. Group 3 shifts to use Line 4 instead of other lines. The passenger flow on Line 4 is relatively low compared to other lines as Line 4 is newly put into operation, which guarantees high travel time reliability.

The mean and the average CV of individual travel times in each commuter group before and after Line 4 opening are listed in Table 2. It can be found that after Line 4 opening the mean travel time of group 1 and group 2 hardly changes. It indicates that for passengers who do not change OD choices the effect of introducing new metro line on average travel time is little. Note that the mean travel time of group 2 commuters slightly decreases. This is because the operation of Line 4 results in reduced number of transfers for some group 2 commuters. However, the average travel time of group 3 significantly increases after Line 4 opening. It indicates that 

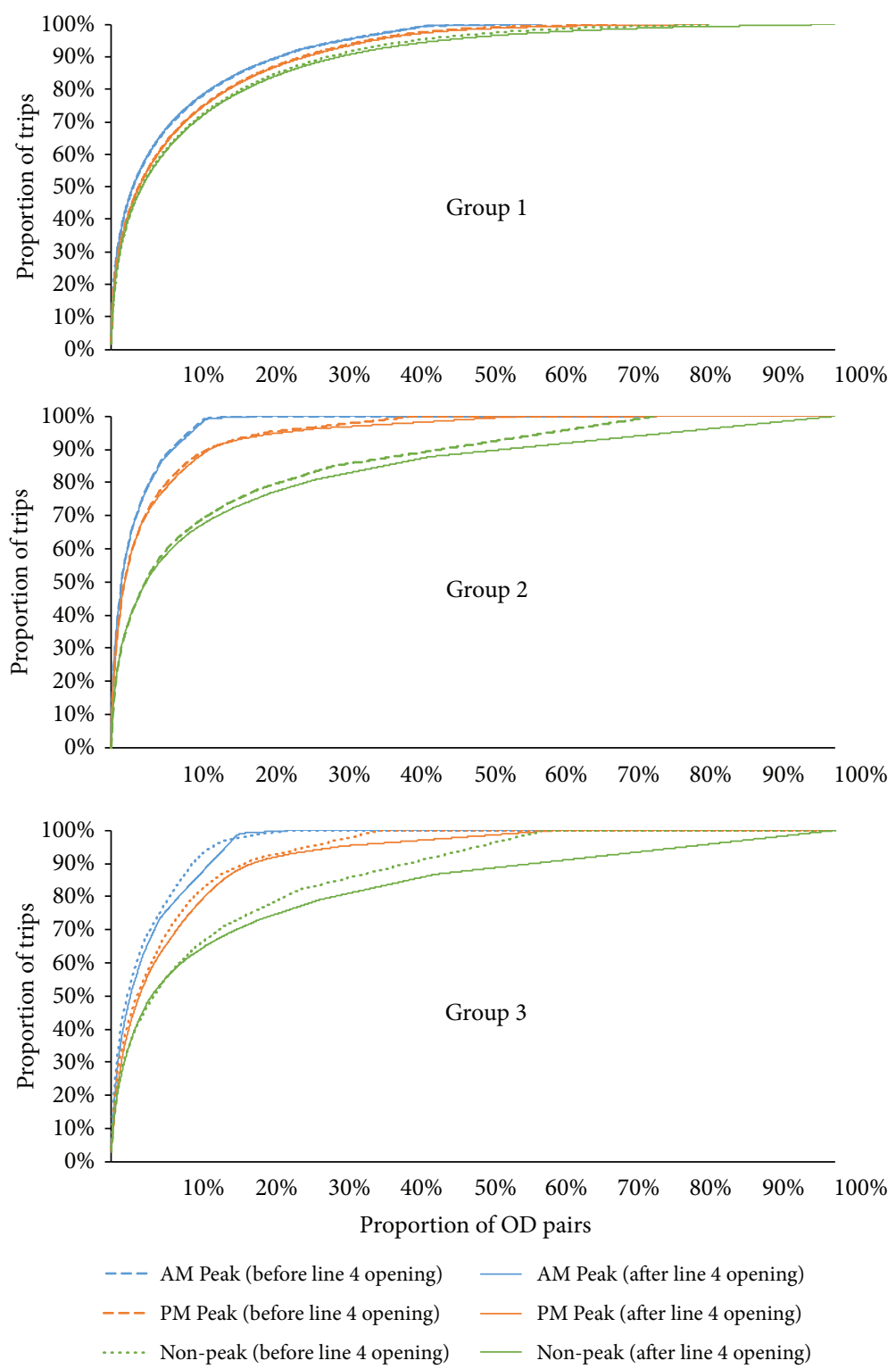

FIGURE 9: Cumulative number of trips with regard to proportion of ODs before and after Line 4 opening.

TABLE 2: Mean and average CV of commuting travel time.

\begin{tabular}{lcccc}
\hline & \multicolumn{2}{c}{ Before Line 4 opening } & \multicolumn{2}{c}{ After Line 4 opening } \\
& Mean (min) & Average CV & Mean (min) & Average CV \\
\hline Group 1 & 25.545 & 0.100 & 25.624 & 0.100 \\
Group 2 & 25.630 & 0.084 & 25.063 & 0.082 \\
Group 3 & 25.975 & 0.096 & 34.306 & 0.086 \\
\hline
\end{tabular}

the new line makes group 3 commuters prefer travelling farther by metro, as the new stations provide commuters with more entrance/exit station choices.

It can be concluded from Table 2 that the new metro line has different levels of impacts on the travel time reliability of commuters in different groups. Introducing Line 4 hardly influences travel time reliability of commuters who do not change their OD choices. The average $\mathrm{CV}$ of group 1 travel time remains stable, while the average $\mathrm{CV}$ of group 2 travel time slightly decreases from 0.084 to 0.082 . The impact of Line 4 on group 3 travel time reliability is significant. The average $\mathrm{CV}$ of group 3 travel time (i.e., the travel time of commuters who shift to use new stations on Line 4) drops from 0.096 to 0.086 . 


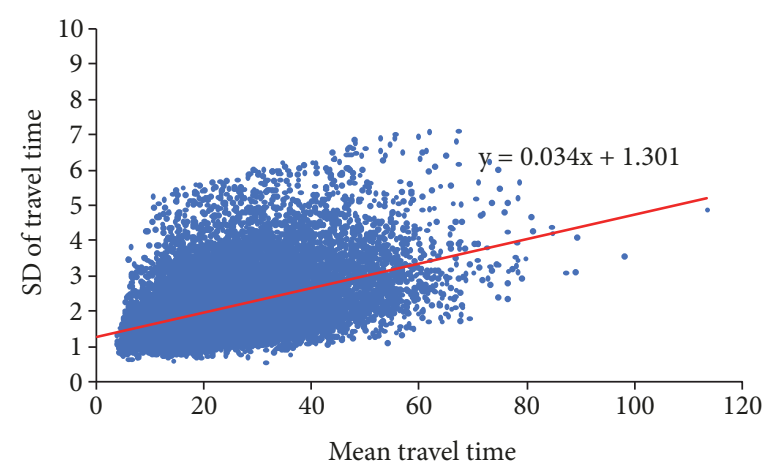

(a) Group 1, before Line 4 opening



(c) Group 2, before Line 4 opening

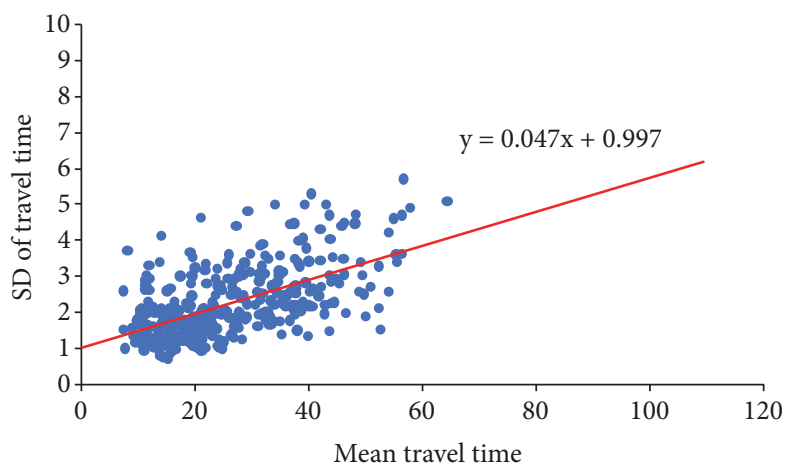

(e) Group 3, before Line 4 opening



(b) Group 1, after Line 4 opening

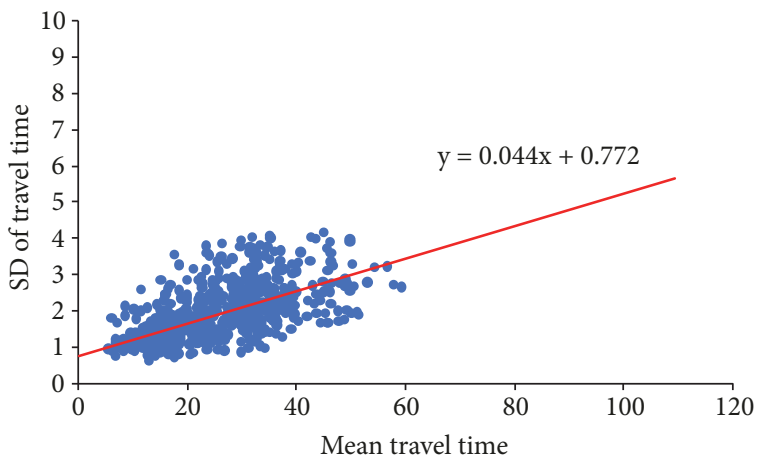

(d) Group 2, after Line 4 opening

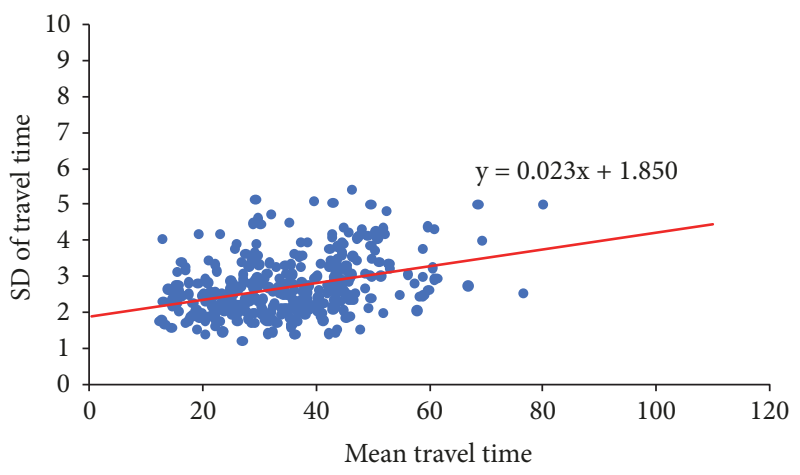

(f) Group 3, after Line 4 opening

FIGURE 10: The mean and the SD of commuting travel time before and after Line 4 opening.

\section{Conclusions}

This paper presents a comprehensive analysis based on smart card data of metro system to demonstrate the effects of rail transit development in urban areas. The impacts of a new metro line (i.e., Line 4 of Nanjing metro) on both the whole metro network and different categories of commuters are investigated by analysing passenger flow distributions, travel times, and travel time reliability.

Analysis of passenger flow at all metro stations is conducted based on the smart card data before and after the opening of a new metro line. It is found that the passenger flow of the whole metro network increases after the new line opening, while the crowding at some metro stations reduced as the new line shares a large proportion of passengers.
To intensively study the impact of the new metro line on the network level, this study investigates the stations with significant change of passenger flow after the opening of the new metro line. Additionally, the travel time and the travel time reliability in the metro network are intensively studied. It is found that the opening of Line 4 leads to changes of travel time and travel time reliability for many stations.

To demonstrate the impact of the new metro line on different categories of commuters, metro commuters are identified and classified according to their OD choices. Flow distribution, travel time, and travel time reliability of different groups of commuters are analysed. The results indicate that the new metro line influences commuters with different OD choices to different degrees. The results in this study provide reference for guiding and evaluating rail transit network 
planning in cities with large populations and have a potential to optimize and coordinate the operation between new transit lines and existing transit lines.

Several directions for further research are worth noting. First, although a big proportion of metro trips in Nanjing are made with smart card, it cannot be assumed that the flow pattern and travel times of passengers with one-way tickets are the same as smart card users. Due to the difficulty of collecting data of one-way tickets, the study presented in this paper can be extended by conducting activity and travel surveys. Second, in this study, smart card data from January to February 2017 are used to investigate the impact of the new metro line. In further research, more data after March 2017 are expected to be obtained to study passenger flow patterns and metro travel times to see how the new line contributes to the whole network after a long-term operation. Third, the analysis of travel time reliability presented in this paper can be extended to reliability-based accessibility by including detailed demographic information and land use data.

\section{Data Availability}

The data used to support the findings of this study can be found in the section of "Study Area and Data Collection".

\section{Conflicts of Interest}

The authors declare that they have no conflicts of interest.

\section{Acknowledgments}

The work described in this paper was jointly supported by the Natural Science Foundation of Jiangsu Province (BK20160676), the National Natural Science Foundations of China (71601045, 71501038, and 41571375), and the Social Science Foundation of Jiangsu Province (16GLC008).

\section{References}

[1] M. Bagchi and P. R. White, "The potential of public transport smart card data," Transport Policy, vol. 12, no. 5, pp. 464-474, 2005.

[2] C. Chen, J. Ma, Y. Susilo, Y. Liu, and M. Wang, "The promises of big data and small data for travel behavior (aka human mobility) analysis," Transportation Research Part C: Emerging Technologies, vol. 68, pp. 285-299, 2016.

[3] C.-J. Cai, E.-J. Yao, S.-S. Liu, Y.-S. Zhang, and J. Liu, "Holiday destination choice behavior analysis based on AFC data of urban rail transit," Discrete Dynamics in Nature and Society, vol. 6, pp. 1-7, 2015.

[4] Y. Sun, J. Shi, and P. M. Schonfeld, "Identifying passenger flow characteristics and evaluating travel time reliability by visualizing AFC data: a case study of Shanghai Metro," Public Transport, vol. 8, no. 3, pp. 341-363, 2016.

[5] Y. Ma, W. Xu, X. Zhao, and Y. Li, "Modeling the hourly distribution of population at a high spatiotemporal resolution using subway smart card data: A case study in the central area of Beijing," ISPRS International Journal of Geo-Information, vol. 6 , no. $5,2017 \mathrm{~b}$.
[6] F. Zhou and R.-H. Xu, "Model of passenger flow assignmentfor Urban rail transit based on entryand exit time constraints," Transportation Research Record, no. 2284, pp. 57-61, 2012.

[7] J. Zhao, F. Zhang, L. Tu et al., "Estimation of Passenger Route Choice Pattern Using Smart Card Data for Complex Metro Systems," IEEE Transactions on Intelligent Transportation Systems, vol. 18, no. 4, pp. 790-801, 2017.

[8] S. Tao, J. Corcoran, F. Rowe, and M. Hickman, "To travel or not to travel: 'Weather' is the question. Modelling the effect of local weather conditions on bus ridership," Transportation Research Part C: Emerging Technologies, vol. 86, pp. 147-167, 2018.

[9] Y. Wang, G. H. D. A. Correia, E. D. Romph, and H. J. P. Timmermans, "Using metro smart card data to model location choice of after-work activities: An application to Shanghai," Journal of Transport Geography, vol. 63, pp. 40-47, 2017.

[10] W. Zhu, W. Wang, and Z. Huang, "Estimating train choices of rail transit passengers with real timetable and automatic fare collection data," Journal of Advanced Transportation, vol. 2017, Article ID 5824051, 12 pages, 2017.

[11] J. Kim, J. Corcoran, and M. Papamanolis, "Route choice stickiness of public transport passengers: Measuring habitual bus ridership behaviour using smart card data," Transportation Research Part C: Emerging Technologies, vol. 83, pp. 146-164, 2017.

[12] W. Jang, "Travel time and transfer analysis using transit smart card data," Transportation Research Record, no. 2144, pp. 142149, 2010.

[13] X. Ma, Y. J. Wu, Y. Wang, F. Chen, and J. Liu, "Mining smart card data for transit riders travel patterns," Transportation Research Part C: Emerging Technologies, vol. 36, pp. 1-12, 2013.

[14] H. Faroqi, M. Mesbah, and J. Kim, "Spatial-temporal similarity correlation between public transit passengers using smart card data," Journal of Advanced Transportation, vol. 4, pp. 1-15, 2017.

[15] J. Zhao, Q. Qu, F. Zhang, C. Xu, and S. Liu, "Spatio-Temporal Analysis of Passenger Travel Patterns in Massive Smart Card Data," IEEE Transactions on Intelligent Transportation Systems, vol. 99, pp. 1-12, 2017a.

[16] K. Kim, K. Oh, Y. K. Lee, S. Kim, and J.-Y. Jung, "An analysis on movement patterns between zones using smart card data in subway networks," International Journal of Geographical Information Science, vol. 28, no. 9, pp. 1781-1801, 2014.

[17] L. Sun and K. W. Axhausen, "Understanding urban mobility patterns with a probabilistic tensor factorization framework," Transportation Research Part B: Methodological, vol. 91, pp. 511524, 2016.

[18] Z. Zhao, H. N. Koutsopoulos, and J. Zhao, "Individual mobility prediction using transit smart card data," Transportation Research Part C: Emerging Technologies, vol. 89, pp. 19-34, 2018.

[19] C. Morency, M. Trépanier, and B. Agard, "Measuring transit use variability with smart-card data," Transport Policy, vol. 14, no. 3, pp. 193-203, 2007.

[20] S. Tao, D. Rohde, and J. Corcoran, "Examining the spatialtemporal dynamics of bus passenger travel behaviour using smart card data and the flow-comap," Journal of Transport Geography, vol. 41, pp. 21-36, 2014.

[21] L.-M. Kieu, A. Bhaskar, and E. Chung, "A modified densitybased scanning algorithm with noise for spatial travel pattern analysis from smart card AFC data," Transportation Research Part C: Emerging Technologies, vol. 58, pp. 193-207, 2015.

[22] E. Manley, Z. Chen, and M. Batty, "Spatiotemporal variation in travel regularity through transit user profiling," Transportation, vol. 45, no. 3, pp. 703-732, 2016. 
[23] L. M. Kieu, A. Bhaskar, and E. Chung, "Passenger segmentation using smart card data," IEEE Transactions on Intelligent Transportation Systems, vol. 16, no. 3, pp. 1537-1548, 2015a.

[24] X. Ma, C. Liu, H. Wen, Y. Wang, and Y. Wu, "Understanding commuting patterns using transit smart card data," Journal of Transport Geography, vol. 58, pp. 135-145, 2017.

[25] J. Y. Park, D.-J. Kim, and Y. Lim, "Use of smart card data to define public transit use in Seoul, South Korea," Transportation Research Record, no. 2063, pp. 3-9, 2008.

[26] Y.-S. Zhang and E.-J. Yao, "Splitting travel time based on AFC Data: Estimating walking, waiting, transfer, and in-vehicle travel times in metro system," Discrete Dynamics in Nature and Society, vol. 1, pp. 1-11, 2015.

[27] M. Bernal, E. W. Welch, and P. S. Sriraj, "The effect of slow zones on ridership: An analysis of the Chicago Transit Authority "El" Blue Line," Transportation Research Part A: Policy and Practice, vol. 87, pp. 11-21, 2016.

[28] J. Chan, Rail transit OD matrix estimation and journey time reliability metrics using automated fare data. MS thesis, Massachusetts Institute of Technology, Cambridge, 2007.

[29] D. Uniman, Service reliability measurement framework using smart card data: application to the London underground. MS thesis, Massachusetts Institute of Technology, Cambridge, 2009.

[30] Z. Liu, Y. Yan, X. Qu, and Y. Zhang, "Bus stop-skipping scheme with random travel time," Transportation Research Part C: Emerging Technologies, vol. 35, pp. 46-56, 2013.

[31] X. Fu, W. H. K. Lam, and B. Y. Chen, "A reliability-based traffic assignment model for multi-modal transport network under demand uncertainty," Journal of Advanced Transportation, vol. 48, no. 1, pp. 66-85, 2014

[32] Z.-L. Ma, L. Ferreira, M. Mesbah, and A. T. Hojati, "Modeling bus travel time reliability with supply and demand data from automatic vehicle location and smart card systems," Transportation Research Record, vol. 2533, pp. 17-27, 2015.

[33] B. Y. Chen, H. Yuan, Q. Li et al., "Measuring place-based accessibility under travel time uncertainty," International Journal of Geographical Information Science, vol. 31, no. 4, pp. 783-804, 2017.

[34] M. L. Senior, "Impacts on travel behaviour of Greater Manchester's light rail investment (Metrolink Phase 1): evidence from household surveys and Census data," Journal of Transport Geography, vol. 17, no. 3, pp. 187-197, 2009.

[35] X. Cao and J. Schoner, "The influences of light rail transit on transit use: an exploration of station area residents along the Hiawatha Line in Minneapolis," in Proceedings of the Transportation Research Board 92nd Annual Meeting, 2013.

[36] J. Harvey, N. Thorpe, M. Caygill, and A. Namdeo, "Public attitudes to and perceptions of high speed rail in the UK," Transport Policy, vol. 36, pp. 70-78, 2014.

[37] J. Gadziński and A. Radzimski, "The first rapid tram line in Poland: How has it affected travel behaviours, housing choices and satisfaction, and apartment prices?" Journal of Transport Geography, vol. 54, pp. 451-463, 2016.

[38] S. Saidi, S. C. Wirasinghe, and L. Kattan, "Long-term planning for ring-radial urban rail transit networks," Transportation Research Part B: Methodological, vol. 86, pp. 128-146, 2016.

[39] A. Hong, M. G. Boarnet, and D. Houston, "New light rail transit and active travel: A longitudinal study," Transportation Research Part A: Policy and Practice, vol. 92, pp. 131-144, 2016.

[40] S. Li, "Influence of a New Subway Line's Opening on Passenger Flow Characteristics of an Urban Rail Transit Network," in
Proceedings of the 15th COTA International Conference of Transportation Professionals: Efficient, Safe, and Green Multimodal Transportation, CICTP 2015, pp. 1756-1769, China, July 2015.

[41] S. Liu, E. Yao, and B. Li, "Exploring urban rail transit stationlevel ridership growth with network expansion," Transportation Research Part D Transport \& Environment.

[42] M.-P. Kwan, "Beyond Space (As We Knew It): Toward Temporally Integrated Geographies of Segregation, Health, and Accessibility: Space-Time Integration in Geography and GIScience," Annals of the Association of American Geographers, vol. 103, no. 5, pp. 1078-1086, 2013.

[43] B. Y. Chen, Y. Wang, D. Wang, Q. Li, W. H. K. Lam, and S. L. Shaw, "Understanding the impacts of human mobility on accessibility using massive mobile phone tracking data," Annals of the American Association of Geographers, vol. 108, pp. 1115$1133,2018$.

[44] X. Fu and W. H. K. Lam, "A network equilibrium approach for modelling activity-travel pattern scheduling problems in multimodal transit networks with uncertainty," Transportation, vol. 41, no. 1, pp. 37-55, 2014.

[45] K. M. N. Habib, L. Kattan, and T. Islam, "Model of personal attitudes towards transit service quality," Journal of Advanced Transportation, vol. 45, no. 4, pp. 271-285, 2011.

[46] H. Wakabayashi and Y. Matsumoto, "Comparative study on travel time reliability indexes for highway users and operators," Journal of Advanced Transportation, vol. 46, no. 4, pp. 318-339, 2012. 


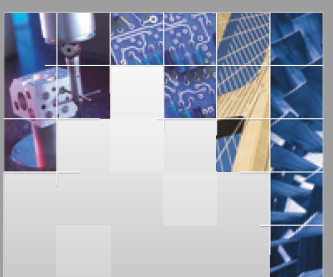

\section{Enfincering}
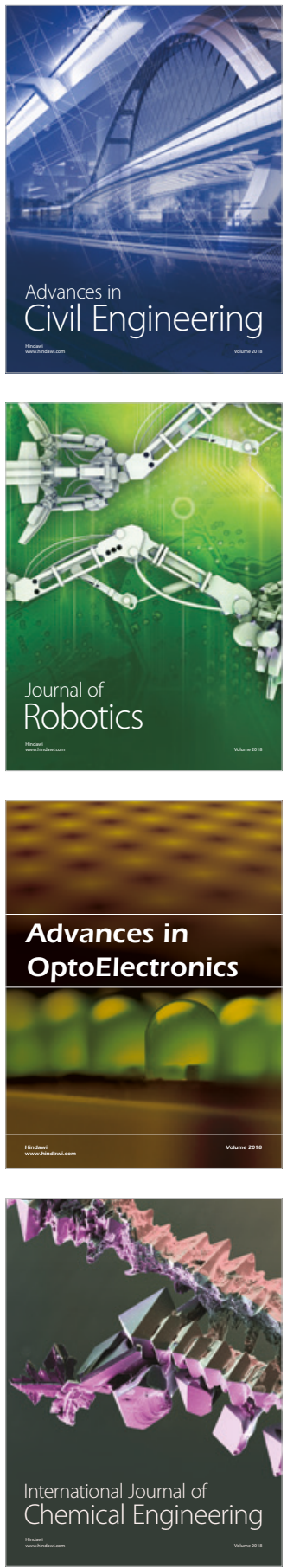

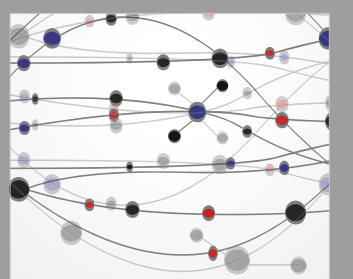

\section{Rotating \\ Machinery}

The Scientific World Journal



Submit your manuscripts at

www.hindawi.com
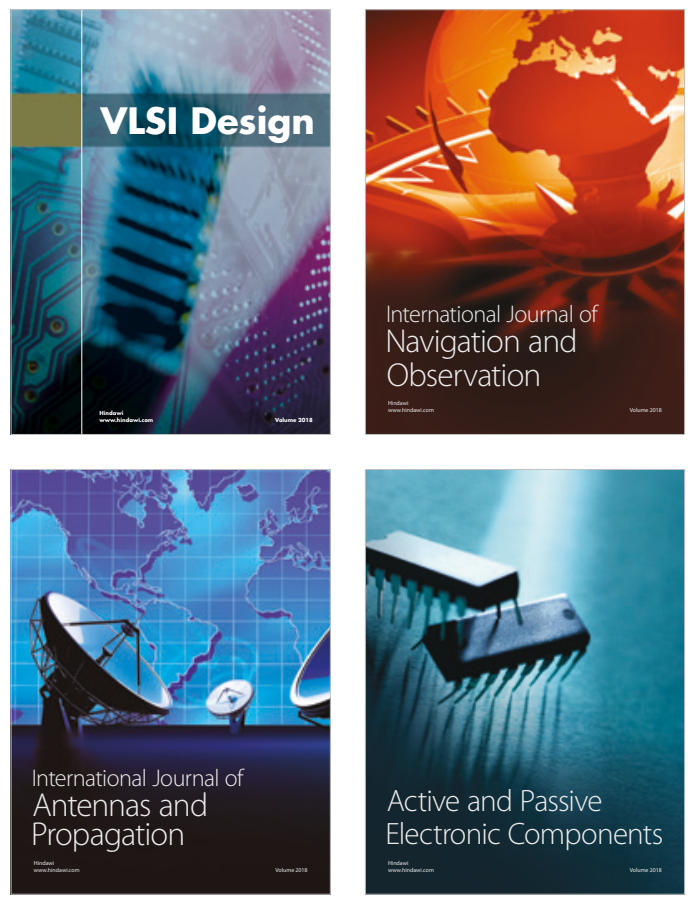
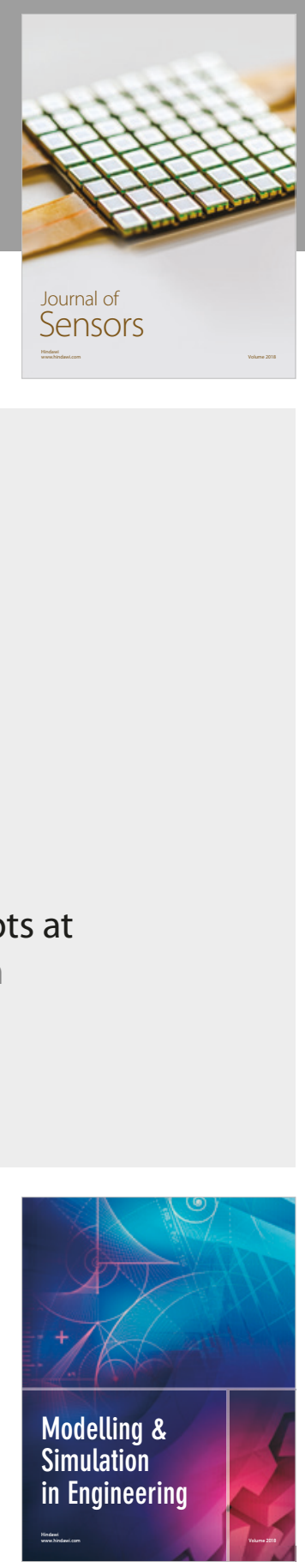

\section{Advances \\ Multimedia}
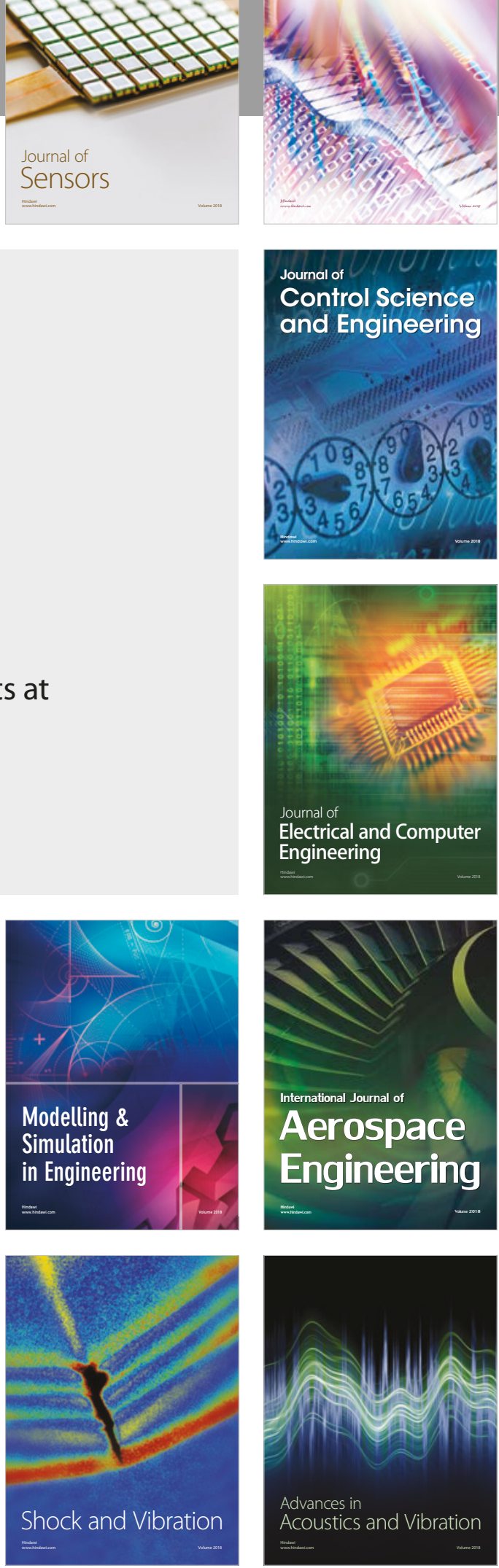